\section{A Case of Idiopathic Intracranial Hypertension due to Chronic Kidney Disease}

\section{Gökhan Gözün, Ömer Jaradat and Bülent Ataş}

Department of Pediatrics, Meram Medical Faculty, Necmettin Erbakan University, Meram, Konya, Turkey

*Corresponding author: Ömer Jaradat, General Practitioner, Department of Pediatrics, Meram Medical Faculty, Necmettin Erbakan University, Meram, Konya, Turkey, Tel: +905533113744; E-mail: omerjaradat94@gmail.com

Received date: September 18, 2018; Accepted date: October 24, 2018; Published date: October 31, 2018

Copyright: () 2018 Gözün G, et al. This is an open-access article distributed under the terms of the Creative Commons Attribution License, which permits unrestricted use, distribution, and reproduction in any medium, provided the original author and source are credited.

\begin{abstract}
Both vesicoureteral reflux and recurrent upper urinary tract infections can cause Chronic Kidney Disease (CKD) and hypertension. Systemic hypertension can develop neurologic symptoms in patients by causing intracranial hypertension, but Pseudotumor Cerebri (PTC) is rare with CKD. Herein, we present an 11 years old girl with neurologic symptoms. CKD, hypertension, and PTC were detected. Through the administered treatment, neurologic symptoms were regressed and blood pressure was controlled.
\end{abstract}

Keywords: Pseudotumor cerebri; Chronic kidney disease; Pediatric; Headache

\section{Introduction}

Vesicoureteral reflux is a major cause of chronic kidney disease in children. Hypertension, renal function impairment, and CKD are long-term squeals of reflux nephropathy $[1,2]$. Permanent renal scars in patients with Vesicoureteral reflux increase the risk of hypertension. Proteinuria and hypertension are both indicators of renal injury. They accelerate the progression of reflux nephropathy to CKD $[1,3]$. The degree of renal parenchymal injury, unilateral or bilateral kidney involvement, and patient's age increase the frequency of hypertension [4]. Systemic hypertension acts a part in the involvement of papilledema, headache, and cranial nerve palsy by causing intracranial hypertension [5].

Pseudotumor cerebri is characterized by increased intracranial pressure in the absence of any intracranial lesions, inflammation, or obstruction. Pseudotumor cerebri most commonly occurs in obese women of childbearing age, but could be seen in children and men. The clinical presentation is characterized by elevated CSF pressure above $250 \mathrm{~mm} \mathrm{H}_{2} \mathrm{O}$ along with symptoms and signs. Patients complain about headache, visual disturbances, and pulsatile tinnitus, while signs include papilledema, visual field defects, and VI nerve palsy. Diagnosis of pseudotumor cerebri require the assessment of CSF (Cerebrospinal Fluid) pressure by lumbar puncture. PTC may cause irreversible visual field defects and visual loss, which makes the early diagnosis so important $[6,7]$. However, the findings at magnetic resonance imaging are non-specific [8]. So that diffusion tensor imaging, which is an advanced MR (Magnetic Resonance) imaging technique, could be used in the diagnosis of pseudotumor cerebri due to well correlation with the degree of papilledema (early or advanced) and visual field defects [9].

Herein, we present an 11 years old girl who presented with neurologic symptoms. PTC, CKD, and hypertension were detected. Through the administered treatment, neurologic symptoms were regressed and blood pressure was controlled.

\section{Case Report}

Eleven years old girl was admitted with headache, nausea, and diplopia which started one day before admission. Fetal USG examinations during perinatal period were normal. The patient was born at term. Her APGAR (Appearance, Pulse, Grimace, Activity, Respiration) score was 8 and 9 on the $1^{\text {st }}$ and $5^{\text {th }}$ min, respectively. She was fed with breast milk immediately after birth. She had jaundice which started at the second day after birth, lasted for 2 days, and treated by phototherapy. The neurological development steps were completely normal. Since infancy the patient confirmed about febrile attacks with pollakiuria, treated by short-term antibiotic therapy.

Her weight and height development were normal, body temperature was $36.8^{\circ} \mathrm{C}$. However blood pressure was $160 / 100 \mathrm{mmHg}$. Ocular examination revealed bilateral papilledema and right esotropia resulting from right-sided VI nerve palsy.

Laboratory studies were as following: Serum urea $65.6 \mathrm{mg} / \mathrm{dL}$ (normal range: $15-44 \mathrm{mg} / \mathrm{dL}$ ), creatinine $1.42 \mathrm{mg} / \mathrm{dL}$ (normal range: $0.72-1.25 \mathrm{mg} / \mathrm{dL}$ ), glomerular filtration ratio was $47 \mathrm{~mL} / \mathrm{min} / 1.73 \mathrm{~m}^{2}$. Complete Blood Count (CBC) was normal and proteinuria was detected on urinalysis. Cranial Magnetic Resonance Imaging (MRI) demonstrated high T2 signal expanding the dural sheath of the right optic nerve, and a reduction in retinal nerve-fiber layer thickness. On renal MRI right kidney was measured 80x35 mm dimension, and left kidney was measured 90x37 mm dimension. Pelvicalyceal structures were locally dilated, and renal parenchyma was thin. On DMSA imaging there was a wide hypoactive field compatible with parenchymal scar at mid section and lower pole of the left kidney and multiple hypoactive fields compatible with renal scars in the right kidney. Radioactivity uptake (the split ratio) seen as $65 \%$ for the left kidney, and 35\% for the right one. Voiding cystourethrogram showed bilateral grade 1 reflux. Lumbar Puncture revealed an opening pressure of $300 \mathrm{~mm} \mathrm{H}_{2} \mathrm{O}$ (normal range: $70-200 \mathrm{~mm} \mathrm{H}_{2} \mathrm{O}$ ). CSF analysis was unremarkable. Due to clinical concerns for PTC, patient was started on acetazolamide and continued for 28 days.

Initial treatment with enalapril was administered because of elevated blood pressure, but efficient control of blood pressure was not 
Page 2 of 3

achieved, thus a combination with amlodipine was started and continued for 18 days.

At the clinical observation: daily blood pressure measurements were normal, serum urea and creatinine were both at normal ranges, GFR measured as $64.09 \mathrm{~mL} / \mathrm{min} / 1.73 \mathrm{~m}^{2}$. Renal MRI angiography showed normal renal arteries. Papilledema and abduction deficit of the right eye started gradually to resolve. At the $20^{\text {th }}$ day of acetazolamide therapy they were both totally recovered. The patient was discharged with amlodipine and acetazolamide.

On outpatient follow up: CBC was normal, serum urea was 50.7 $\mathrm{mg} / \mathrm{dL}$, creatinine was $1.19 \mathrm{mg} / \mathrm{dL}$, GFR was $68.4 \mathrm{~mL} / \mathrm{min} / 1.73 \mathrm{~m}^{2}$, and proteinuria was still detectable on urinalysis. Acetazolamide therapy continued for 8 months until papilledema had fully recovered.

Control LP was about to be performed, but patient's family refused. This limited us to confirm the clinical recovery with regulated CSF pressure value.

\section{Discussion}

Vesicoureteral reflux and pyelonephritis in children could cause reflux nephropathy which is a risk factor for renal scar and hypertension [10]. Immune responses against urinary substances are the suspected reason of microvascular injury ongoing with endothelium loss, bacterial infection and irritation [11]. It is believed that the hypertension evolved from renal scars is caused by segmental ischemia ongoing with increased renin secretion [12]. Hypertension accelerates renal injury and the early detection helps in decreasing mortality and morbidity. In CKD cases hypertension is a known risk factor in progression to End Stage Renal Disease (ESRD) [13,14] Hypertension affects at least $10 \%$ of children with renal scars. On the other hand hypertension does not develop in some pediatric patients despite of having renal scars [15]. Our case had severe malign hypertension. Because of febrile urinary tract infection history, VCUG evaluation suggests reflux nephropathy to be the cause of CKD. Patients with renal scars may come with hypertension any time later, as in our case. It should be emphasized that patients who come in this way may have an underlying nephropathy, and shows that both early diagnosis and treatment of pyelonephritis at young ages are very important for long term kidney survival.

Pseudotumor cerebri is a diagnosis of exclusion, so that other causes of increased intracranial pressure must be ruled out. Our patient had an extensive evaluation including imaging studies of the brain and CSF analysis, which were unremarkable. However, the pathogenesis of PTC is unknown. There are default mechanisms suggested to cause PTC, such as increased CSF outflow resistance at the level of arachnoid granulations or lymphatic drainage sites; cerebral venous outflow abnormalities (such as venous stenosis); altered sodium and water retention mechanisms [16,17]. There are many case reports of conditions that are associated with PTC, but case reports of PTC with $\mathrm{CKD}$ are limited. One of these studies was about PTC developed in a male patient with CKD. His neurologic symptoms persisted until dialysis was started [18]. This case may establish the relation between uremia and PTC, despite the unknown underlying pathophysiology. Furthermore, animal and pathology studies have shown that severe renal failure could be associated with slightly elevated intracranial pressures [19-22].

\section{Conclusion}

We report a case of 11 years old girl with PTC, CKD, and hypertension. Her neurologic symptoms were regressed after medical therapy. The clinical importance of this case is uncertain, due to lack of control CSF pressure measurement because of family refusal. Despite this, it is a very rare presentation of renal disease, with neurological manifestation secondary to intracranial hypertension, with symptom regression after medical therapy. In the end, this maybe medically relevant or a coincidence, but it was an unusual observation.

\section{References:}

1. Brakeman P (2008) Vesicoureteral reflux, reflux nephropathy and end stage renal disease. Adv Urol 2008: 508949.

2. Cendron M (2008) Reflux nephropathy. J Pediatr Urol 4: 414-421.

3. Mattoo TK (2011) Vesicoureteral reflux and reflux nephropathy. Adv Chronic Kidney Disease 18: 348-354.

4. Smith EA (2008) Pyelonephritis, renal scarring, and reflux nephropathy: A pediatric urologist's perspective. Pediatr Radiol 38: 76-82.

5. Wall M, Kupersmith MJ, Kieburtz KD (2014) The idiopathic intracranial hypertension treatment trial: Clinical profile at baseline. JAMA Neurol 71: 693.

6. Markey KA, Mollan SP, Jensen RH, Sinclair AJ (2016) Understanding idiopathic intracranial hypertension: Mechanisms, management, and future directions. Lancet Neurol 15:78-91.

7. Willenborg KD, Nacimiento W (2015) Characteristic neurological features, differential diagnostic criteria and medicinal treatment of idiopathic intracranial hypertension. Ophthalmologe 112: 814-820.

8. Bidot S, Saindane AM, Peragallo JH, Bruce BB, Newman NJ, et al. (2015) Brain imaging in idiopathic intracranial hypertension. $J$ Neuroophthalmol 35: 400-411.

9. Razek AAKA, Batouty N, Fathy W, Bassiouny R (2018) Diffusion tensor imaging of the optic disc in idiopathic intracranial hypertension. Neuroradiology: 1-8.

10. Sargent MA (2000) What is the normal prevalence of vesicoureteral reflux? Pediatr Radiol 30: 587-593.

11. Hodson CJ, Maling TMJ, McManamon PJ (1875) The pathogenesis of reflux nephropathy. Br J Radiol 48: 1-26.

12. Jacobson SH, Jacobson SH, Eklof O, et al. (1992) Long-term prognosis of post-infectious renal scarring in relation to radiological findings in childhood-a 27-year follow-up. Pediatr Nephrol 6:19-24.

13. Smellie JM, Edwards D, Hunter N (1975) Vesicoureteric reflux and renal scarring. Kidney Int Suppl 8: 65-72.

14. Pylkkänen J, Vilska J, Koskimies O (1981) The value of level diagnosis of childhood urinary tract infection in predicting renal injury. Acta Paediatr Scand 70: 879-883.

15. Arar MY, Hogg RJ, Arant BSJ (1994) Etiology of sustained hypertension in children in the southwestern United States. Pediatr Nephrol 8: 186-189.

16. Johnston IH, Duff J, Jacobson EE, Fagan E (2001) Asymptomatic intracranial hypertension in disorders of CSF circulation in childhoodtreated and untreated. Pediat Neurosurg 34: 63-72.

17. Biousse V, Bruce BB, Newman NJ (2012) Update on the pathophysiology and management of idiopathic intracranial hypertension. J Neurol Neurosurg Psychiatry 83: 488-494.

18. Chang D, Nagatomo G, Smith WE (1992) Benign intracranial hypertension and chronic renal failure. Cleve Clin J Med 59: 419-422.

19. Rodríguez E, Delucchi A, Cano F (1992) Neurotoxicity caused by cyclosporine A in renal transplantation in children. Rev Med Chil 120: 300-303.

20. Gilliland KG, Hegstrom RM (1963) The effect of hemodialysis on cerebrospinal fluid pressure in uremic dogs. Trans Am Soc Artif Intern Organs 9: 44-48.

21. Steen O (1961) The brain in uremia. Acta Psychiatr Scand 43: 1-65. 
Citation: Gözün G, Jaradat O, Atas B (2018) A Case of Idiopathic Intracranial Hypertension due to Chronic Kidney Disease. J Pediatr Neurol Med 3: 134. doi:10.4172/2472-100X.1000134

22. Raskin NH, Fishman RA (1976) Neurologic disorders in renal failure, part 1. N Engl J Med 294: 143-148. 